\title{
Power Quality Improvement in Faulty Conditions using Tuned Harmonic Filters
}

\author{
Sumit Kanwar ${ }^{1}$, Om Prakash Mahela ${ }^{2}$, Devendra Mittal ${ }^{3}$ \\ ${ }^{I}$ (Senior Lecturer, Department of Electrical Engineering, Asians Institute of Technology, Jaipur, India) \\ ${ }^{2}$ (Graduate Student Member IEEE \& Junior Engineer-I, RRVPNL, Jodhpur, India) \\ ${ }^{3}$ (Assistant Professor, Department of Electrical Engineering, Jagannath University, Jaipur, India)
}

\begin{abstract}
The Electrical power quality has become an important topic of discussion and research these days. As per IEEE 519 std. parameters of power quality measurement, are four in number, of which Total Harmonic Distortion is most widely used. This paper proposes the optimal planning of passive tuned harmonic filters for improvement of power quality in faulty conditions of electrical power system. The Total Harmonic Distortion analysis of power quality disturbances is carried out in the faulty conditions and in the presence of single tuned and double tuned harmonic filters. The four bus system having two load and two generator buses is modeled in MATLAB/Simulink environment. A fault is created near the load bus and power quality disturbances are detected near the generator bus and improved using single tuned and double tuned filters near the generator bus under study. The Matlab results show the performance of double tuned filter in improvement of power quality disturbances during faulty conditions.
\end{abstract}

Keywords - power quality disturbances, total harmonic distortion, power system fault, single tuned harmonic filter, double tuned harmonic filter.

\section{INTRODUCTION}

The continuous monitoring of power quality (PQ) has become imperative as occurrences of $\mathrm{PQ}$ disturbances are relatively sporadic and mostly unscheduled. Further when something goes wrong and the source of the problem needs to be investigated, whether upstream or downstream of the issue, $\mathrm{PQ}$ data is an absolute necessity [1]. Power quality is a term used to describe the most important aspect of the electricity supply. Power quality can be defined as any problem manifested in voltage, current, or frequency deviation that results in failure or mal-operation of electric equipment [2]. Poor quality of electric power is normally caused by power line disturbances, such as impulses, notches, glitches, momentary interruption wave faults, voltage sag, swell, harmonic distortion and flicker resulting in misoperation or failure of end use equipments [3]. Poor quality may cause many problems that affect the load such as malfunction, instability, short lifetime and so on. According to the survey by IEEE transactions on Industrial Applications, power quality disturbances lead to losses of $\$ 4$ billion to $\$ 10$ billion in the USA alone [4]. In recent years, grid users have detected an increasing number of drawbacks caused by electric power quality (PQ) variations and $\mathrm{PQ}$ problems have sharpened because of the increased number of loads sensitive to PQ and have become more difficult to solve as the loads themselves have become important causes of degradation of quality [5]. Transmission line relaying involves the three major tasks: detection, classification, and location of the fault. It must be done as fast and accurate as possible to de-energize the faulted line and protecting the system from the harmful effects of the fault. With the wide application of high power electronics switchgears, problems of power quality are becoming more serious day by day [6]-[7]. The power quality disturbances depend on amplitude or frequency or on both frequency and amplitude. Based on duration of existence of PQ disturbances, events can be divided in short, medium or long type. The classification and identification of each disturbance are usually carried out from standards and recommendations depending on where the utilities operate (e.g. IEEE in the U.S.). Inigo Monedero et al. [8] defined PQ disturbances, based on the UNE standard in Spain which defines the ideal signal as a single-phase or three-phase sinusoidal voltage signal of $230 \mathrm{~V}_{\mathrm{RMS}}$ and $50 \mathrm{~Hz}$. D. Saxena et al. [9] classified various PQ events in to five groups viz. short duration variation, long duration variation, transients, voltage imbalance and waveform distortion. S.Edwin Jose et al. [10] classified PQ disturbances on basis of values of tails of histogram obtained from simulation results. Haibo He et al.[11] proposed a novel approach for the power quality disturbances classification based on the wavelet transform and self organizing learning array system. Devendra Mittal et al. [12] presented a method for improvement of electrical power quality under faulty conditions in electrical power system using three phase double tuned harmonic filter.

Most of papers published on power quality are concerned with the customer related issues and classification of power quality disturbances. This paper aims improvement of power quality in faulty conditions of power system using three phase single tuned and double tuned harmonic filters. The four bus system with two load and two generator buses is simulated in MATLAB/Simulink environment. The power quality improvement 
using three phase harmonic filters connected at generator bus during LG fault, LL fault, LLG fault, LLL fault and LLLG fault on the load bus has been studied. The analysis is carried out on the basis of Total harmonic Distortion (THD). The results obtained after simulation demonstrate the performance of three phase harmonic filters in improvement of power quality during faulty conditions of power system.

\section{Three-PhaSe TunED HARMONIC FILTERS}

The passive harmonics filters are composed of passive elements: resistor $(\mathrm{R})$, inductor $(\mathrm{L})$ and capacitor (C). The common types of passive filters include single-tuned and double tuned filters, second-order, third-order and C-type damped filters. Three-phase harmonic filters are shunt elements that are used in power systems for decreasing voltage distortion and for power factor correction. The three-phase harmonic filter is built of RLC elements. The resistance, inductance and capacitance values are determined from the filter type, reactive power at nominal voltage, tuning frequencies and quality factor. Passive filter has been widely used in filtering harmonics in power system because it has a simple structure, low cost and high reliability. The single tuned filter is the series combination of inductor $(\mathrm{L})$ and capacitor $(\mathrm{C})$ as shown in Fig. 1. Usually, there are multiple frequency harmonics in a power system, so a group of parallel single tuned filters are needed to filter harmonics. This filtering method covers a large area and has a high cost [13].

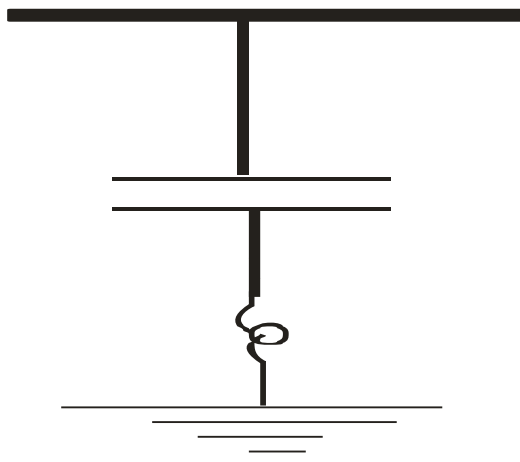

Fig. 1 Single tuned harmonic filter

Double tuned filter performs the same function as two single tuned filters connected in parallel although it has certain advantages of lower cost, low losses and lower impedance magnitude at the frequency of parallel resonance that arises between the two tuning frequencies [14]. Chih-Ju et al.[15] presented that double tuned filter consists of a series LC circuit and a parallel RLC circuit as shown in Fig. 2. If $f_{1}$ and $f_{2}$ are the two tuning frequencies, both the series circuit and parallel circuit are tuned to approximately the mean geometric frequency given by the relation:

$$
f_{m}=\sqrt{f_{1} \times f_{2}}
$$

The quality factor $\mathrm{Q}$ of the double tuned filter is defined as the quality factor of the parallel $\mathrm{L}, \mathrm{R}$ elements at the mean frequency $\mathrm{f}_{\mathrm{m}}$ :

$$
Q=\frac{R}{L \times 2 \pi f_{m}}
$$

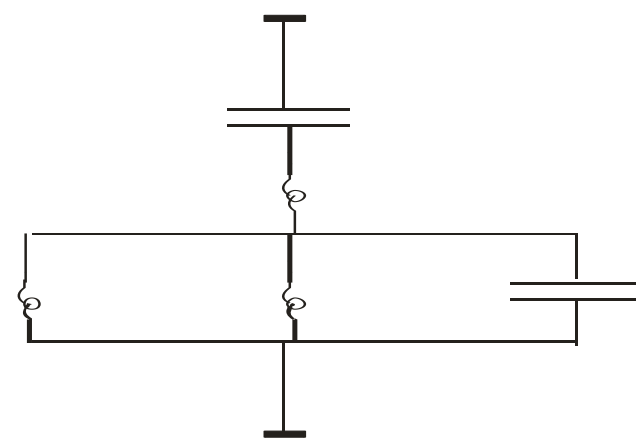

Fig. 2 Double tuned harmonic filter

\section{TOTAL HARMONIC DISTORTION}

Non-sinusoidal input, or supply, current is made up of fundamental current plus current components of higher frequencies. The total harmonic distortion (THD) is equal to the rms value of all the harmonics divided 
by the rms value of fundamental component of the input current. Greater the value of THD greater is the harmonic content and hence greater is the distortion of input supply current [16]. The THD is given by the relation given below:-

$$
T H D=\frac{I_{h}}{I_{s 1}}=\frac{\sqrt{I_{s}^{2}-I_{s 1}^{2}}}{I_{s 1}^{2}}=\frac{\sum_{n=2}^{\infty} I_{s n}}{I_{s 1}}
$$

Where $\quad I_{h}=$ rms value of all the harmonic components combined

$\mathrm{I}_{\mathrm{sn}}=$ rms value of $\mathrm{nth}$ harmonic content.

$I_{s}=$ rms value of supply phase current including fundamental and harmonics.

\section{PROPOSED POWER SYSTEM MODEL}

For power quality improvement using three-phase single tuned and double tuned harmonic filters during faulty conditions in the power system, the one line diagram of experimental set up consisting of four buses shown in Fig. 3 is used [17]. The buses $1 \& 2$ are taken as generator buses and buses $3 \& 4$ are taken as load buses. The line length of all the four $\pi$ sections are taken as $100 \mathrm{Km}$. For simplicity the voltage levels at all points of the power system are taken as $33 \mathrm{KV}$. The three-phase tuned harmonic filters are installed near the generator bus 1 to protect the generator from power system disturbances during faulty conditions. The fault is located at bus no. 4 in all faulty conditions considered in the study. All the measurement of the voltage signals are taken on bus no. 1 at generating station.

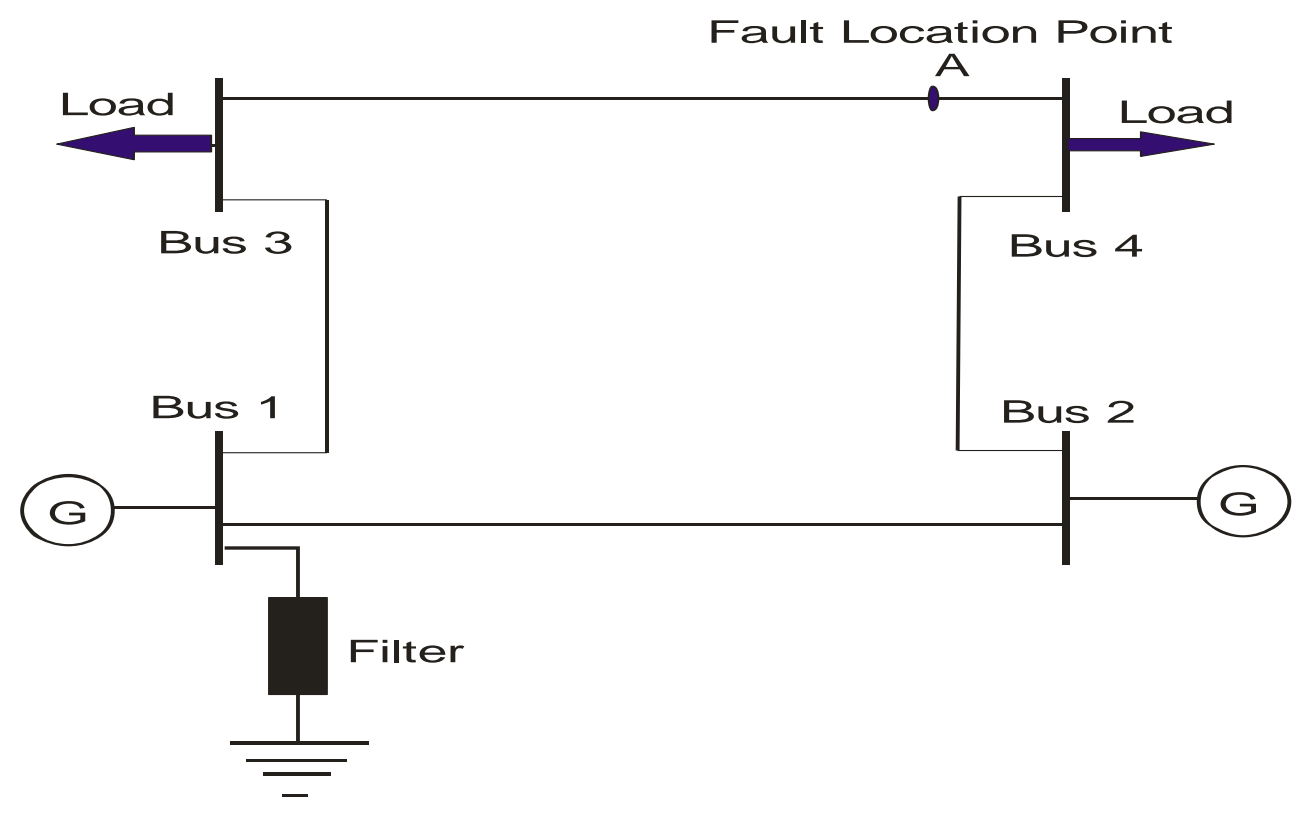

Fig. 3 Proposed model of power system for improvement of PQ disturbances in faulty conditions using tuned harmonic filters

\section{POWER SYSTEM SIMULATION AND DISCUSSION}

Power system faults are abnormal events which are not part of normal operation and unwanted by the network operator. After fault occurs in the power system, a non-linear signal of transient travelling wave is generated and runs along faulted transmission line to both ends of the line. Those travelling waves contain information about fault nature. The fault initial travelling wave has a wide frequency spectrum from DC component to high frequencies. When such fault travelling wave arrives at the substation bus bar, it will change incisively, i.e. travelling wave head will present the sudden change in the time-frequency diagram. In that way, travelling wave arrival to the measuring point (usually the busbar voltage transformers) exactly a moment of sudden change recorded on measuring substation [18]. For experimental improvement of power quality disturbances to reduce the impact of $\mathrm{PQ}$ disturbances on the generators three-phase single tuned and double tuned harmonic filter are used. The proposed model is simulated in MATLAB/Simulink environment for analysis of improvement in the power quality disturbances. The analysis of power quality improvement in the proposed model is based on the total harmonic distortion (THD). The simulation is carried out in three conditions viz. faulty system before filtering, faulty system after filtering using single tuned harmonic filter and faulty system after filtering using double tuned filter. 


\section{V.1 LG Fault in Power System}

The power system model shown in Fig. 3 is simulated in MATLAB/Simulink environment with line to ground fault at bus no. 4 on phase-A. The THD analysis of voltage signal of phase-A during line to ground fault before filtering is shown in Fig. 4. The higher order frequency of integral multiple of fundamental frequency up to $500 \mathrm{~Hz}$ is observed. The observed THD is $3.60 \%$.

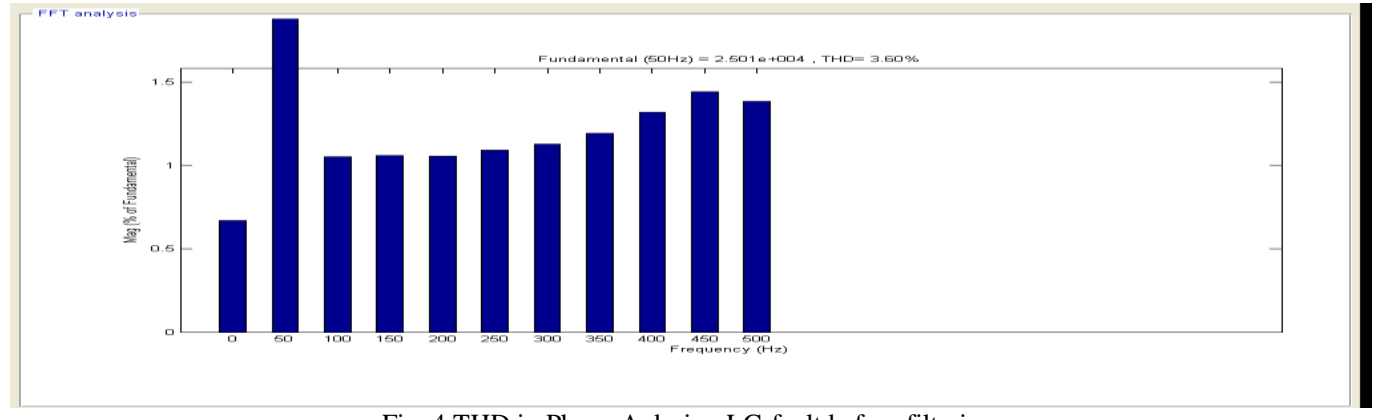

Fig. 4 THD in Phase-A during LG fault before filtering

The THD analysis of voltage signal of phase-A during line to ground fault after using single tuned filter is shown in Fig. 5. The higher order frequency of integral multiple of fundamental frequency up to $900 \mathrm{~Hz}$ is observed. The observed THD is $2.65 \%$.

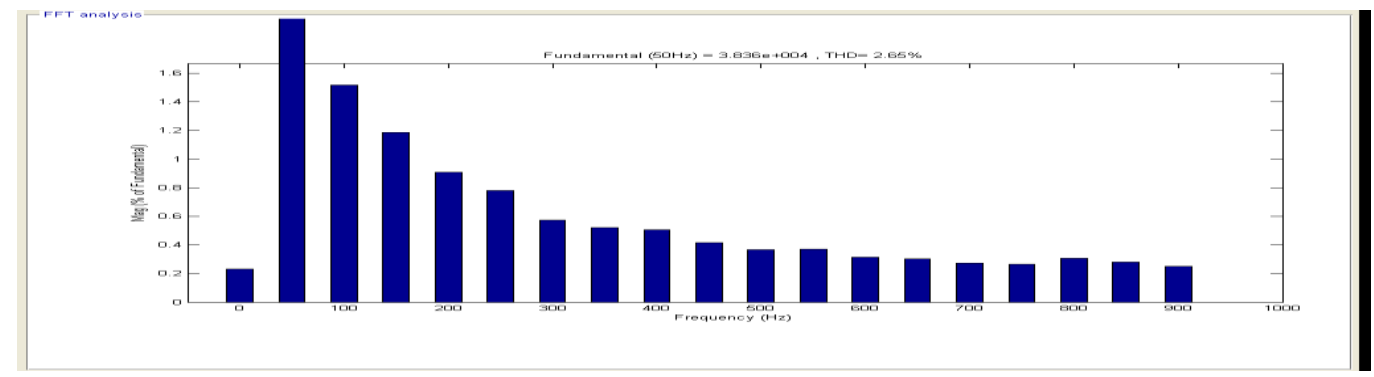

Fig. 5 THD in Phase-A during LG fault after filtering using single tuned filter

The THD analysis of voltage signal of phase-A during line to ground fault after using double tuned filter is shown in Fig. 6. The higher order frequency of integral multiple of fundamental frequency up to $850 \mathrm{~Hz}$ is observed. The observed THD is $1.26 \%$.

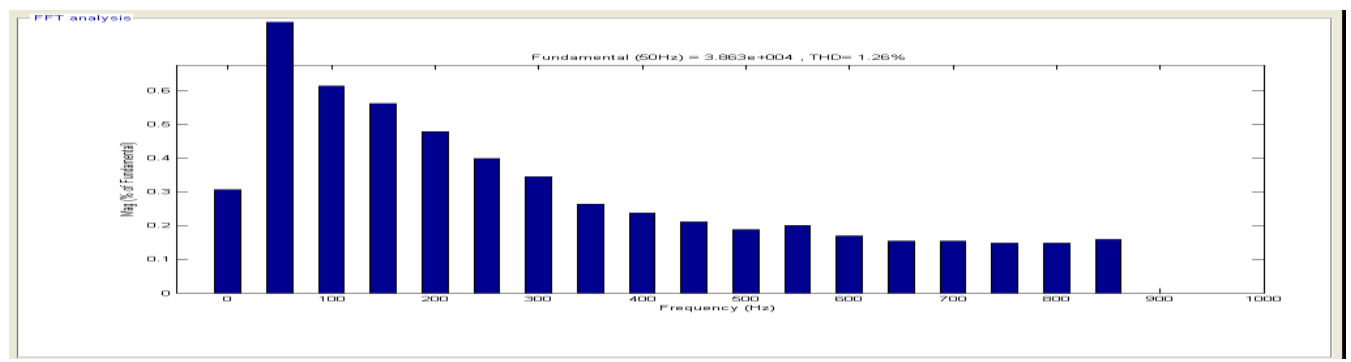

Fig. 6 THD in Phase-A during LG fault after filtering using double tuned filter

\section{V.2 LL Fault on Power System}

The power system model shown in Fig. 3 is simulated in MATLAB/Simulink environment with double line fault between phases A and B at bus no. 4. The THD analysis of voltage signal of phase-A during double line fault before filtering is shown in Fig. 7. The higher order frequency of integral multiple of fundamental frequency up to $750 \mathrm{~Hz}$ is observed. The observed THD is $3.52 \%$. 


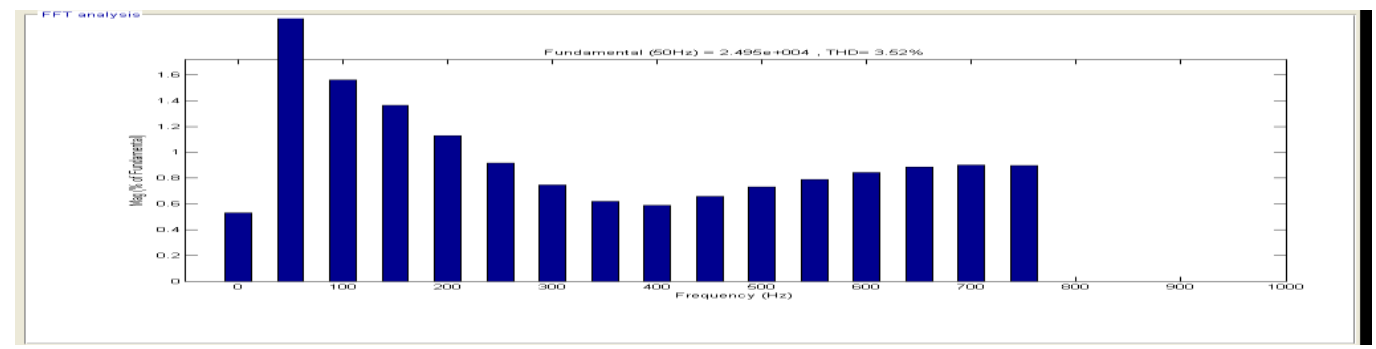

Fig. 7 THD in Phase-A during LL fault on phases A and B before filtering

The THD analysis of voltage signal of phase-A during double line fault after using single tuned filter is shown in Fig. 8. The higher order frequency of integral multiple of fundamental frequency up to $800 \mathrm{~Hz}$ is observed. The observed THD is $1.35 \%$.

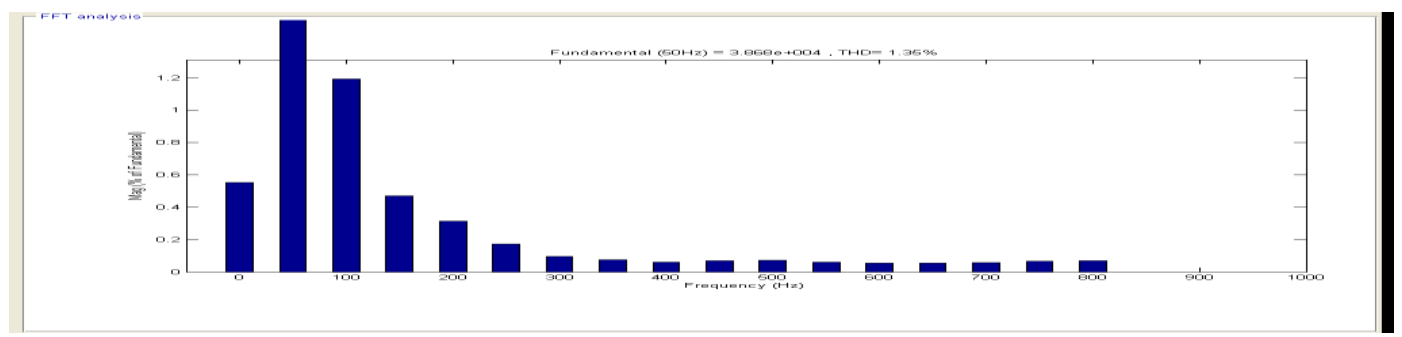

Fig. 8 THD in Phase-A during LL fault on phases A and B after filtering using single tuned filter

The THD analysis of voltage signal of phase-A during double line fault after using double tuned filter is shown in Fig. 9. The higher order frequency of integral multiple of fundamental frequency up to $950 \mathrm{~Hz}$ is observed. The observed THD is $1.14 \%$.

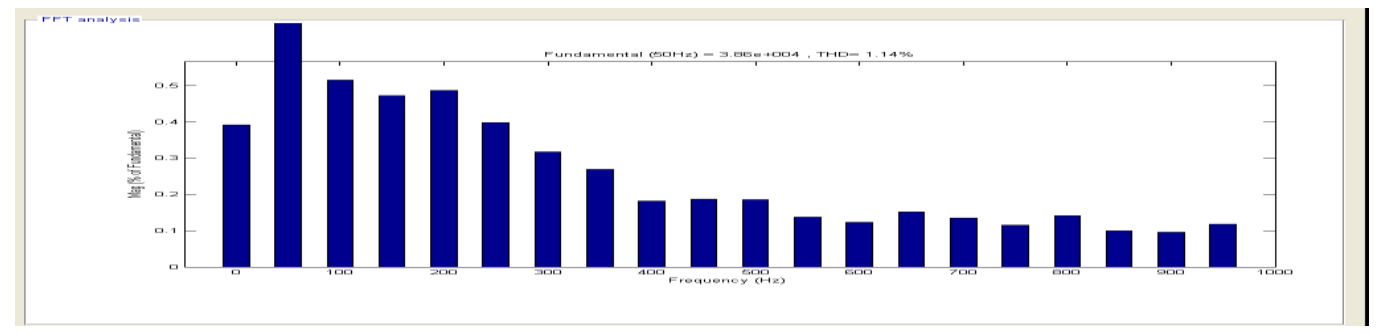

Fig. 9 THD in Phase-A during LL fault on phases A and B after filtering using double tuned filter

\section{V.3 LLG Fault on Power System}

The power system model shown in Fig. 3 is simulated in MATLAB/Simulink environment with double line to ground fault between phases A and B at bus no. 4. The THD analysis of voltage signal of phase-A during double line to ground fault before filtering is shown in Fig. 10. The higher order frequency of integral multiple of fundamental frequency up to $200 \mathrm{~Hz}$ is observed. The observed THD is $7.55 \%$.

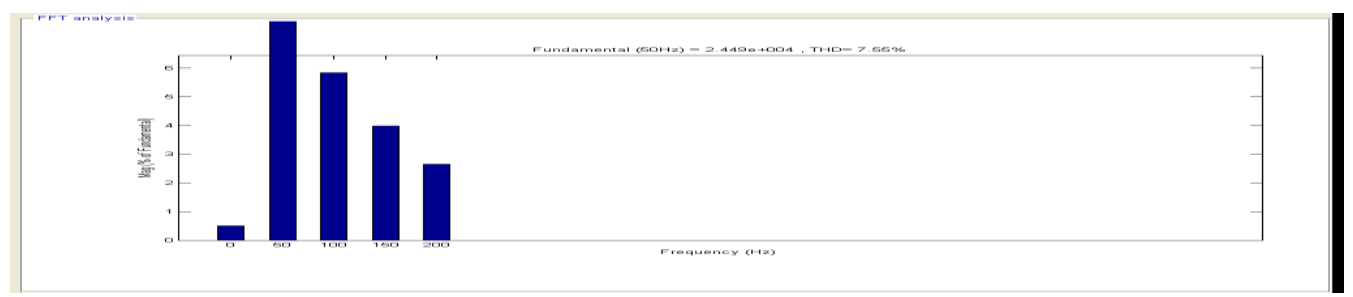

Fig. 10 THD in Phase-A during LLG fault on phases A and B before filtering

The THD analysis of voltage signal of phase-A during double line to ground fault after using single tuned filter is shown in Fig. 11. The higher order frequency of integral multiple of fundamental frequency up to $650 \mathrm{~Hz}$ is observed. The observed THD is $2.01 \%$. 


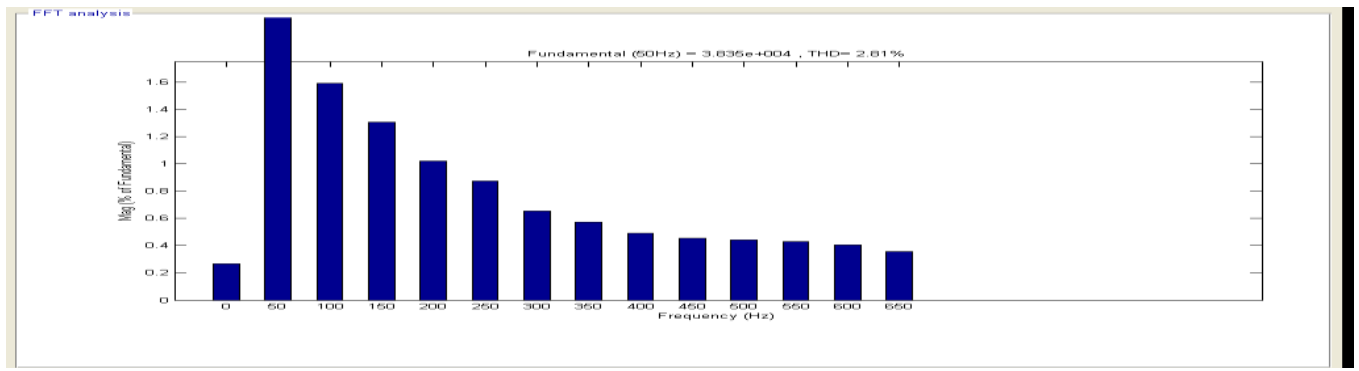

Fig. 11 THD in Phase-A during LLG fault on phases A and B after filtering using single tuned filter

The THD analysis of voltage signal of phase-A during double line to ground fault after using double tuned filter is shown in Fig. 12. The higher order frequency of integral multiple of fundamental frequency up to $700 \mathrm{~Hz}$ is observed. The observed THD is $1.03 \%$.

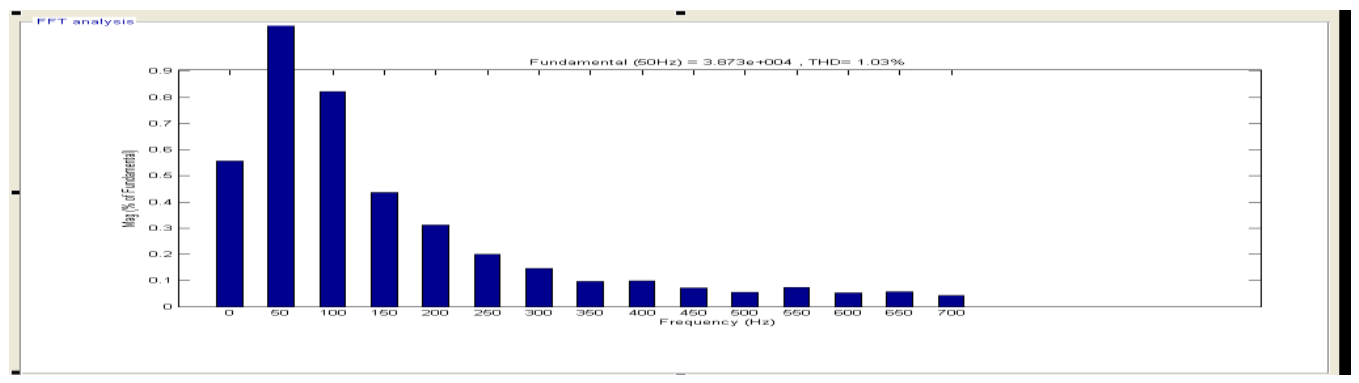

Fig. 12 THD in Phase-A during LL fault on phases A and B after filtering using double tuned filter

\section{V.4 LLL Fault on Power System}

The power system model shown in Fig. 3 is simulated in MATLAB/Simulink environment with three phase fault at bus no. 4. The THD analysis of voltage signal of phase-A during three phase fault before filtering is shown in Fig. 13. The higher order frequency of integral multiple of fundamental frequency up to $900 \mathrm{~Hz}$ is observed. The observed THD is $6.40 \%$.

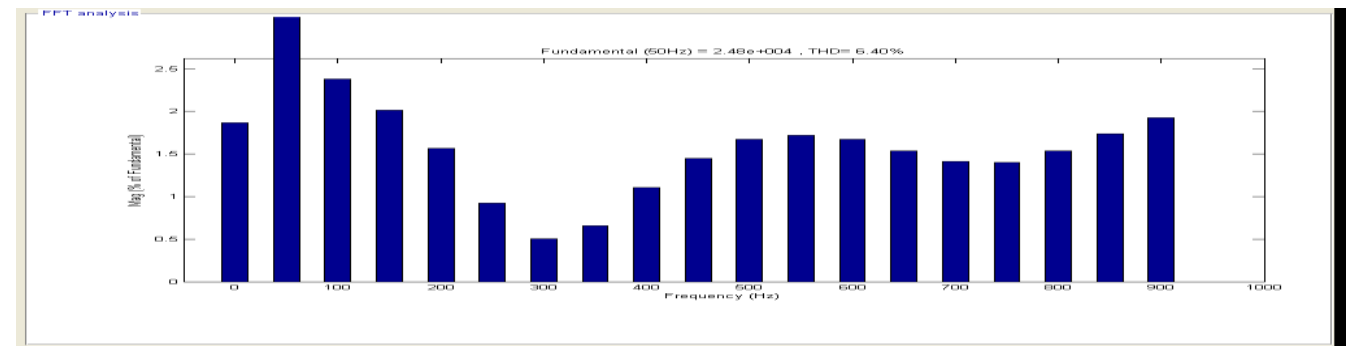

Fig. 13 THD in Phase-A during LLL fault before filtering

The THD analysis of voltage signal of phase-A during three phase fault after using single tuned filter is shown in Fig. 14. The higher order frequency of integral multiple of fundamental frequency up to $850 \mathrm{~Hz}$ is observed. The observed THD is $1.46 \%$.

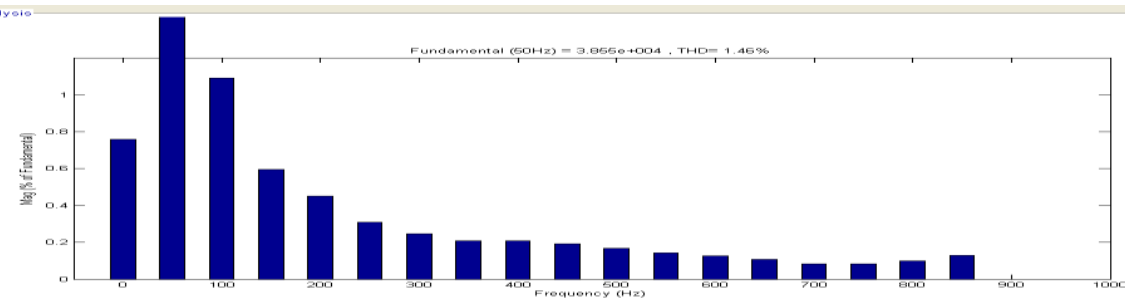

Fig. 14 THD in Phase-A during LLL fault after filtering using single tuned filter 
The THD analysis of voltage signal of phase-A during three phase fault after using single tuned filter is shown in Fig. 15. The higher order frequency of integral multiple of fundamental frequency up to $900 \mathrm{~Hz}$ is observed. The observed THD is $1.55 \%$.

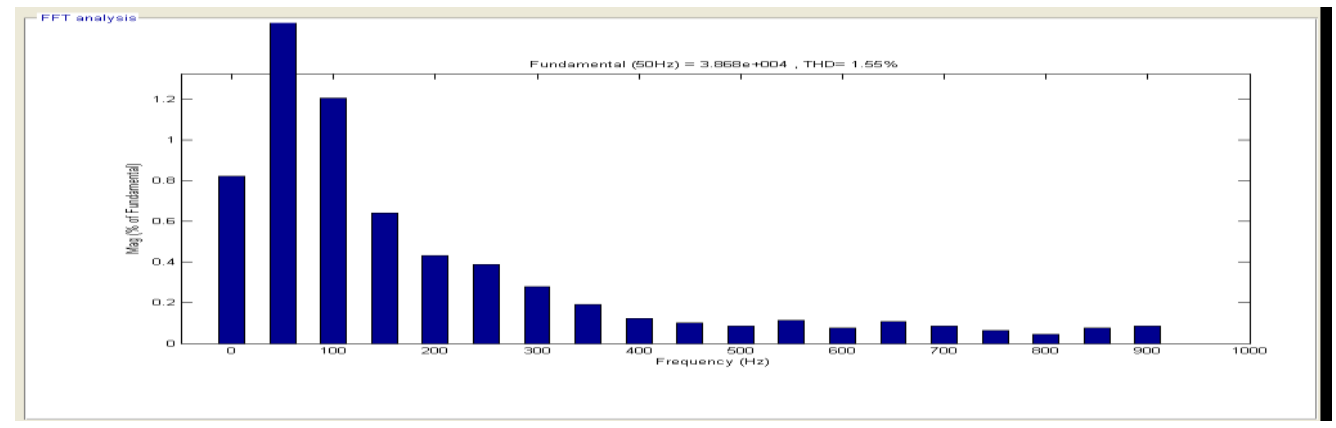

Fig. 15 THD in Phase-A during LLL fault after filtering using double tuned filter

\section{V.5 LLLG Fault on Power System}

The power system model shown in Fig. 3 is simulated in MATLAB/Simulink environment with three phase fault involving ground at bus no. 4. The THD analysis of voltage signal of phase-A during three phase fault involving ground before filtering is shown in Fig. 16. The higher order frequency of integral multiple of fundamental frequency up to $200 \mathrm{~Hz}$ is observed. The observed THD is $9.55 \%$.

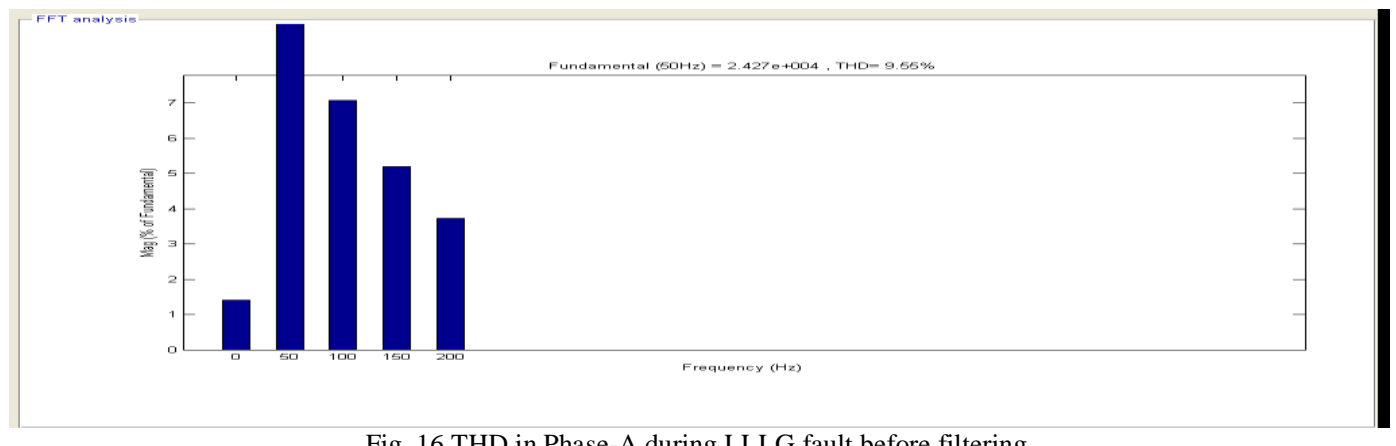

Fig. 16 THD in Phase-A during LLLG fault before filtering

The THD analysis of voltage signal of phase-A during three phase fault involving ground after using single tuned filter is shown in Fig. 17. The higher order frequency of integral multiple of fundamental frequency up to $350 \mathrm{~Hz}$ is observed. The observed THD is $6.70 \%$.

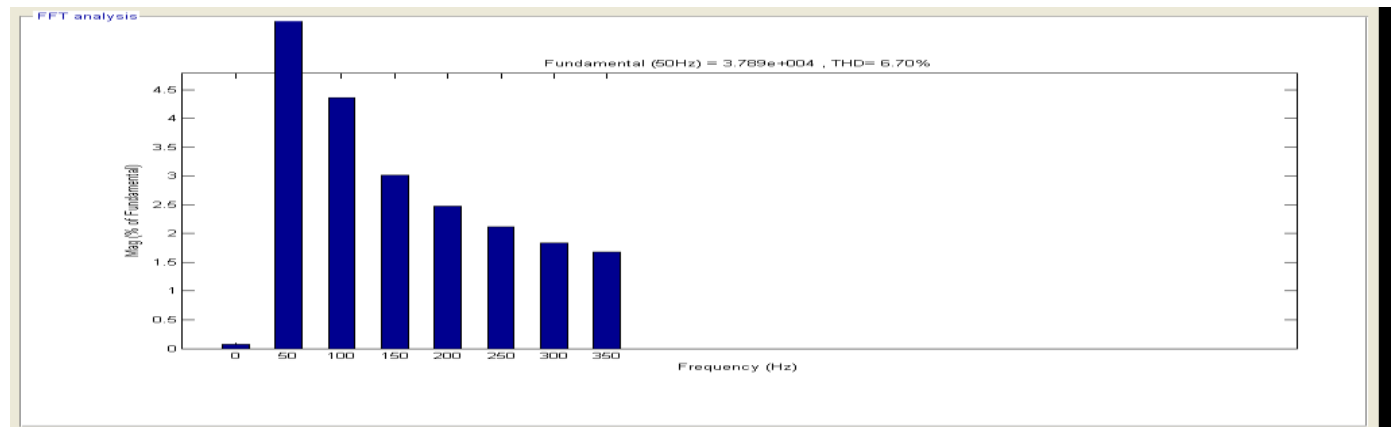

Fig. 17 THD in Phase-A during LLLG fault after filtering using single tuned filter

The THD analysis of voltage signal of phase-A during three phase fault involving ground after using single tuned filter is shown in Fig. 18. The higher order frequency of integral multiple of fundamental frequency up to $950 \mathrm{~Hz}$ is observed. The observed THD is $3.19 \%$. 


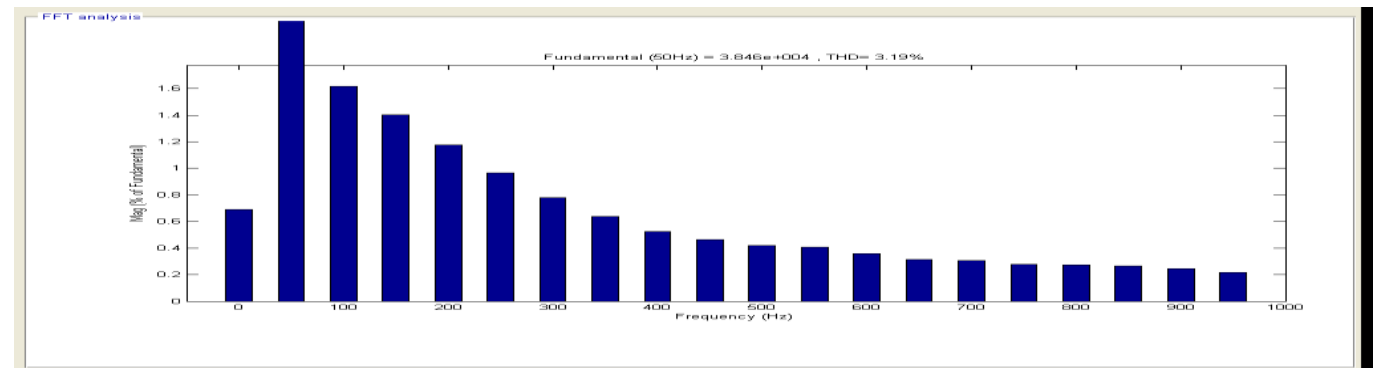

Fig. 18 THD in Phase-A during LLLG fault after filtering using double tuned filter

The total harmonic distortion (THD) of voltage signal at generator bus no. 1 of proposed power system model during different faulty conditions when fault is created at bus no. 4 are shown in Table. 1. The three conditions before filtering, after using single tuned filter and after using double tuned filter are discussed.

TABLE 1

TOTAL HARMONIC DISTORTION OF VOLTAGE SIGNAL IN FAULTY CONDITION

\begin{tabular}{|c|c|c|c|c|}
\hline S.No. & Type of Fault & $\begin{array}{c}\text { THD Before } \\
\text { Filtering }\end{array}$ & $\begin{array}{c}\text { THD After } \\
\text { Using Single } \\
\text { Tuned Filter }\end{array}$ & $\begin{array}{c}\text { THD After Using } \\
\text { Double Tuned } \\
\text { Filter }\end{array}$ \\
\hline 1 & Line to Ground(LG) & $3.60 \%$ & $2.65 \%$ & $1.26 \%$ \\
\hline 2 & Double Line (LL) & $3.52 \%$ & $1.35 \%$ & $1.14 \%$ \\
\hline 3 & Double Line to Ground (LLG) & $7.55 \%$ & $2.01 \%$ & $1.03 \%$ \\
\hline 4 & Three Phase Fault (LLL) & $6.40 \%$ & $1.46 \%$ & $1.55 \%$ \\
\hline 5 & $\begin{array}{c}\text { Three Phase Fault involving } \\
\text { ground (LLLG) }\end{array}$ & $9.55 \%$ & $6.70 \%$ & $3.19 \%$ \\
\hline
\end{tabular}

\section{CONCLUSION}

An efficient but simple technique has been developed for improvement of power quality disturbances during faulty conditions using three phase tuned harmonic filters in the electrical power system. The proposed model of four bus system is simulated in the MATLAB/Simulink environment. The analysis of improvement of power quality during faulty conditions of power system using tuned harmonic filters is carried out using the total harmonic distortion. The results show that three-phase harmonic filters are effective in improvement of power quality in faulty conditions. The double tuned harmonic filter is comparatively more effective as compared to the single tuned harmonic filter. The THD reduces in all faulty conditions while using single tuned filter which further reduces on using double tuned filter. The tuned harmonic filters are effective in protecting the costly equipment of power system transients during faulty conditions.

\section{REFERENCES}

[1] Manoj Gupta, Rajesh Kumar, and Ram Awtar Gupta, "Neural Network Based Indexing and Recognition of Power Quality Disturbances," TELKOMNIKA, Vol. 9, No.2, August 2011, pp. 227-236.

[2] R.Dugan, M. McGranaghan, and H. Wane Beaty, Electrical Power Systems Quality, McGraw-Hill, Ney York, 1996.

[3] Subhamita Roy, and Sudipta Nath, "Classification of power quality disturbances using features of signals," International Journal of Scientific and Research Publications, Vol. 2, Issue 11, November 2012, pp.01-09.

[4] He H., Shen X, and Starzyk J.A., "Power quality disturbances analysis based on EDMRA method," Electrical Power and Energy System, Vol. 31, pp. 258-268.

[5] P.Daponte, M.di Penta, and G. Mercurio, Transientmeter: A distuributed measurement system for power quality monitoring," Proceeding $9^{\text {th }}$ International Conference Harmonics and Quality of Power, 2000, Vo. 3, pp.1017-1022.

[6] M.Sushama, G.Tulasi Ram Das, and A.Jaya Laxmi, "Mitigation of voltage sags with dynamic voltage restorer using wavelets," Presented at the International Conference RACE 2007, March 22-24, 2007.

[7] Anoop Mathew, and Benisker Raja Singh D., "Image compression using lifting based DWT," International Journal of Computers Information Technology and Engineering, Vol. 3, January 2009, pp. 27-31.

[8] Inigo Monedero, Carlos Leon, Jorge Ropero, Antonio Garcia, Jose Manuel and Juan C. Montano, “Classification of Electrical Disturbances in Real Time Using Neural Networks," IEEE Transaction on Power Delivery, 2007, pp.1-9.

[9] D. Saxena, K.S. Verma and S.N. Singh, "Power quality event classification: an overview and key issues," International Journal of Engineering, Science and Technology, Vol. 2, No.3, 2010, pp. 186-199.

[10] S.Edwin Jose, and S.Titus, "Detection and classification of power quality using adaptive decomposition structure and neural network," European Journal of Scientific Research, Vol.89, No.3, October 2012, pp. 477-489.

[11] Haibo He, and Janusz A. Starzyk, "A self-organizing learning array system for power quality classification based on wavelet transform," IEEE Transaction on Power Delivery, Vol. 21, No. 1, January 2006, pp.286-295.

[12] Devendra Mittal, Om Prakash Mahela, and Rohit Jain, "Electrical power quality improvement in faulty conditions using three phase double tuned harmonic filter," International Journal of Innovative Research and development, Vol. 2, Issue 6, June 2013, pp.493509 . 
[13] He Yi-hong, and SU Heng, “A new method of designing double tuned filter," Proceedings of the $2^{\text {nd }}$ International Conference on Computer Science and Electronics Engineering, ICCSEE 2013, Paris, France.

[14] Wang Zhaoan, and Yang Jun, Harmonic suppression and reactive power compensation, (Beijing: China Machine Press, 2010).

[15] Chih-Ju, and Chih-Wen Liu, "Optimal planning of large passive-harmonic filters set at high voltage level," IEEE transactions on Power Systems, Vol. 15, No. 1, February 2000, pp. 433-441.

[16] Dr. P.S. Bimbhra, Power Electronics, Khanna Publications, New Delhi, 2011.

[17] Devendra Mittal, Om Prakash Mahela, and Rohit Jain, "Detection and analysis of power quality disturbances under faulty conditions in electrical power system," IAEME-International Journal of Electrical Engineering \& Technology, Vol. 4, Issue 2, March-April 2013, pp. 25-36.

[18] Alen Bernadic, and Zbigniew Leonowicz, "Power line fault location using the complex space-phasor and Hilbert-huang transform," Przeglad Elektrotechniczny (Electrical Review), R.87 NR 5/2011, pp. 204-207.

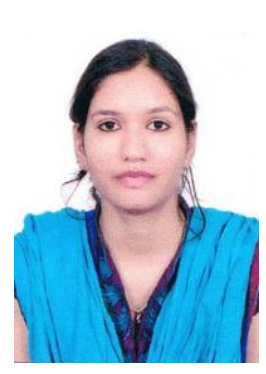

BIOGRAPHIES

Sumit Kanwar studied at Rajasthan College of Engineering for Women and received the B.Tech. in Electrical Engineering from Rajasthan Technical University, Kota, India, in 2010. She received Master's degree in Electrical Engineering from the Jagannath University, Jaipur, India in 2013 with specialization on Power System.

From 2010 to 2011, she was Assistant Professor with the Maharani Girls Engineering College, Jaipur, India. Since 2011 she has been senior lecturer with the Electrical Engineering department of the Asians Institute of Technology, Jaipur, India. Her special fields of interest are power electronics in power system, applications of AI techniques in power system and power quality.

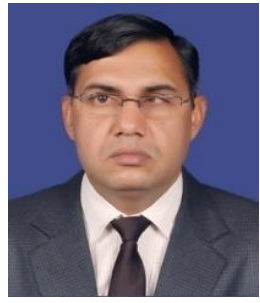

Om Prakash Mahela was born in Sabalpura (Kuchaman City) in the Rajasthan state of India, on April 11, 1977. He studied at Govt. College of Engineering and Technology (CTAE), Udaipur, and received the electrical engineering degree from Maharana Pratap University of Agriculture and Technology (MPUAT), Udaipur, India in 2002. He received M.Tech.(Electrical Engineering) with power system specialization from Jagannath University, Jaipur, India in 2013. He is currently pursuing PhD from Indian Institute of Technology Jodhpur.

From 2002 to 2004, he was Assistant Professor with the RIET, Jaipur. Since 2004, he has been Junior Engineer-I with the Rajasthan Rajya Vidhyut Prasaran Nigam Ltd., Jodhpur, India. His special fields of interest are Transmission and Distribution (T\&D) grid operations, Power Electronics in Power System, Power Quality, Load Forecasting and Integration of Renewable Energy with Electric Transmission and Distribution Grid, Applications of AI Techniques in power system. He is an author of 26 International Journals and Conference papers. He is a Graduate Student Member of IEEE. He is member of IEEE Communications Society. He is Member of IEEE Power \& Energy Society. He is Fellow Member of IAEME. He is Reviewer of TJPRC International Journal of Electrical and Electronics Engineering Research. Mr. Mahela is recipient of University Rank certificate from MPUAT, Udaipur, India, in 2002. He is recipient of university first Rank in M.Tech. from Jagannath University, Jaipur, India in 2013.

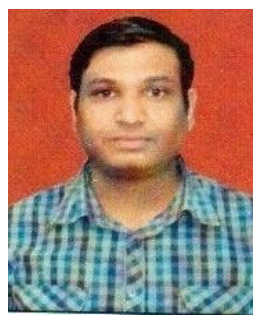

Devendra Mittal was born in Bhusawar in the Rajasthan state of India, on March 17, 1980. He studied at IET, Alwar, and received the electrical engineering degree from Rajasthan University, Jaipur, in 2003. He received M.Tech.(Power system) from MNIT, Jaipur, in 2007. He is currently pursuing Phd from Jagannath University, Jaipur.

From 2003 to 2008, he was Lecturer with Shankara Institute of Technology, Jaipur. From 2008 to 2009, he was Lecturer with UDML Engineering College. Since 2009, he has been Assistant Professor with Jagannath University, Jaipur, India. His special fields of interest are Power Electronics and Power System. 